\title{
Spatio-temporal variations in precipitation on the Huang-Huai-Hai Plain from 1963 to 2012
}

\author{
Yanan $\mathrm{Li}^{1,2,3}$, Zhixiang Xie ${ }^{1,2}$, Yaochen Qin ${ }^{1,2, *}$ and Shenghui Zhou ${ }^{1,2}$ \\ ${ }^{1}$ College of Environment and Planning, Henan University, Kaifeng 475004, Henan, People's Republic of China. \\ ${ }^{2}$ Key Laboratory of Geospatial Technology for the Middle and Lower Yellow River Regions, Ministry of Education, \\ Kaifeng 475004, Henan, People's Republic of China. \\ ${ }^{3}$ Zhengzhou Tourism College, Zhengzhou 450009, Henan, People's Republic of China. \\ *Corresponding author.e-mail: qinyc@henu.edu.cn
}

MS received 5 January 2017; revised 6 February 2018; accepted 8 February 2018; published online 29 August 2018

Spatio-temporal variations in precipitation are affecting agricultural production in China in the context of climate change. Based on daily precipitation data from 63 national meteorological stations on the HuangHuai-Hai Plain from 1963 to 2012, this paper analysed the spatio-temporal variations in precipitation in terms of precipitation days and intensity, using spatial interpolation, linear trend estimation and wavelet analysis. The results indicated that: (i) from 1963 to 2012, the number of annual precipitation days and intensity decreased gradually from the southeast to the northwest. Additionally, the distribution of the extreme precipitation index was similar to that of the annual precipitation index; (ii) the number of annual precipitation days and heavy precipitation days gradually decreased, while precipitation intensity and extreme precipitation days and extreme rainfall intensity remained relatively stable or decreased. The spatial patterns of annual variation trends were considerably different. The annual precipitation days and intensity trends are consistent with the overall trend, while that of the extreme rainfall index in some regions differs from the overall trend; (iii) the precipitation index displayed different periodic oscillations during the period, and the precipitation index values differed at different time scales. However, all the precipitation index values exhibited a 28-yr oscillation.

Keywords. Spatio-temporal variation; precipitation days; intensity; extreme precipitation; HuangHuai-Hai Plain.

\section{Introduction}

Global climate change has resulted in more frequent extreme precipitation events and further enhanced the imbalance of the spatio-temporal distributions of water resources (Trenberth 1998; Ragab and Prudhomme 2002). This imbalance not only affects the industrial and agricultural production but is also a threat to human lives, health and property and has therefore attracted more studies worldwide (IPCC 2012). By setting different precipitation thresholds, Liao et al. (2011) found that the spatial distribution of precipitation in China was highly correlated with the distribution of drought and flood disasters. Xu et al. (2014) studied the spatio-temporal variations in rainfall intensity across China and noticed an increase in moderate and light rain intensities, while larger than moderate rainfall intensities were relatively stable. Based on daily precipitation data from 1961 
to 2011, Ren et al. (2014) found that the extreme precipitation index exhibited obvious spatial trends that, in general, decreased from the southeast to the northwest. Based on an analysis of daily precipitation data from 76 meteorological stations in the Yellow River Basin, He and He (2014) found that the frequency of extreme precipitation is increasing related to the extreme precipitation intensity, and that each extreme precipitation index yielded an increasing trend to various degrees. Gu et al. (2016) found that the floods in the central, midwestern and northwestern China exhibited a trend of significant increase, even in the drought-prone northwest area, accompanied by a significant increase in grain loss rate and yield loss. It is clear that researchers in China have made considerable progress on extreme precipitation events. However, most of the studies are conducted at the global and national level, and studies at the mesoscale and microscale are relatively rare (Beguería et al. 2011; Zeng and Lu 2015; Parker and Abatzoglou 2016). Further, most of the studies have concentrated on the frequency, intensity, variations, trends and causes of extreme rainfall, while studies on the relationship between extreme precipitation events and the grain yield are rare (Moberg and Jones 2005; Fan et al. 2012; Liu et al. 2012; Li et al. 2013; Yang et al. 2014; Guo et al. 2016; Najafi and Moazami 2106). Also, extreme rainfall events are mainly studied with a linear trend and the Mann-Kendall abrupt change test, while the variable characteristics and periodic fluctuations of extreme precipitation events are rarely studied ( $\mathrm{Ci}$ et al. 2014; Rashid et al. 2015).

The Huang-Huai-Hai Plain is an important grain production base for food security in China with its sown area of $20.4 \%$ of the nation's farmland and $23.6 \%$ of the whole nation's grain yield (Yin et al. 2016). The long-term spatio-temporal variations in precipitation in this area are complicated, and are affected by the interaction among factors such as monsoons, the terrain and distance from the coastal areas. With large regional, seasonal and inter-annual precipitation variations, it is one of the most sensitive areas to climate change in China. The regional climate in winter is typically dry and cold; spring is characterised by drought, limited rain and strong evaporation; summer is characterised by high temperatures and large amounts of rainfall, including high-intensity rainfall that often causes summer floods. This area is densely populated, has a large industrial establishment and therefore plays a pivotal role in economic and social developments in China. Drought and flood disasters on the Huang-Huai-Hai Plain caused by precipitation anomalies have always been the main factors that affect and restrict the development of the regional economy and society. This paper aims at the characterisation of spatio-temporal variations in precipitation on the Huang-Huai-Hai Plain from 1963 to 2012 to provide a reference for agricultural production adapting to climate change, industrial distribution, and disaster prevention and mitigation.

\section{Data and methods}

\subsection{Data sources}

Daily precipitation data from 1951 to 2012 were sourced from the Chinese meteorological date hub (http://www.escience.gov.cn/metdata/page/ index.html) and used to produce the precipitation indices in this study. To ensure the integrity of the observation data and retain as many date sites as possible, sites with missing 5-day data were flagged. Then, data from nearby sites was used to fill date gaps in these sites. Finally, meteorological stations with time series $<50 \mathrm{yr}$ are removed, and the daily precipitation data from 63 meteorological stations from 1963 to 2012 was extracted for the analysis (figure 1).

In meteorology, $>0.1 \mathrm{~mm}$ of daily precipitation is defined as a rainy day (Frich et al. 2002), while heavy rain days are defined as days with daily precipitation between 25 and $49.9 \mathrm{~mm}$, and the rainstorm days are defined as days with daily precipitation $\geq 50 \mathrm{~mm}$. The annual precipitation days are the sum of all rainy days, including heavy rain days and rainstorm days throughout the year, the precipitation amount is the total precipitation over a period of time, and the precipitation intensity is the ratio of precipitation amount and precipitation days (Dong et al. 2014). Firstly, in accordance with the definition of meteorology, we used SQL server database to calculate the annual precipitation days, precipitation intensity, heavy rain days, heavy rain intensity, rainstorm days and rainstorm intensity of each meteorological station. Then, we calculated the annual average number of each station and the average numbers for all stations of each year, respectively, to reflect the spatial and the temporal variations of precipitation indices. 


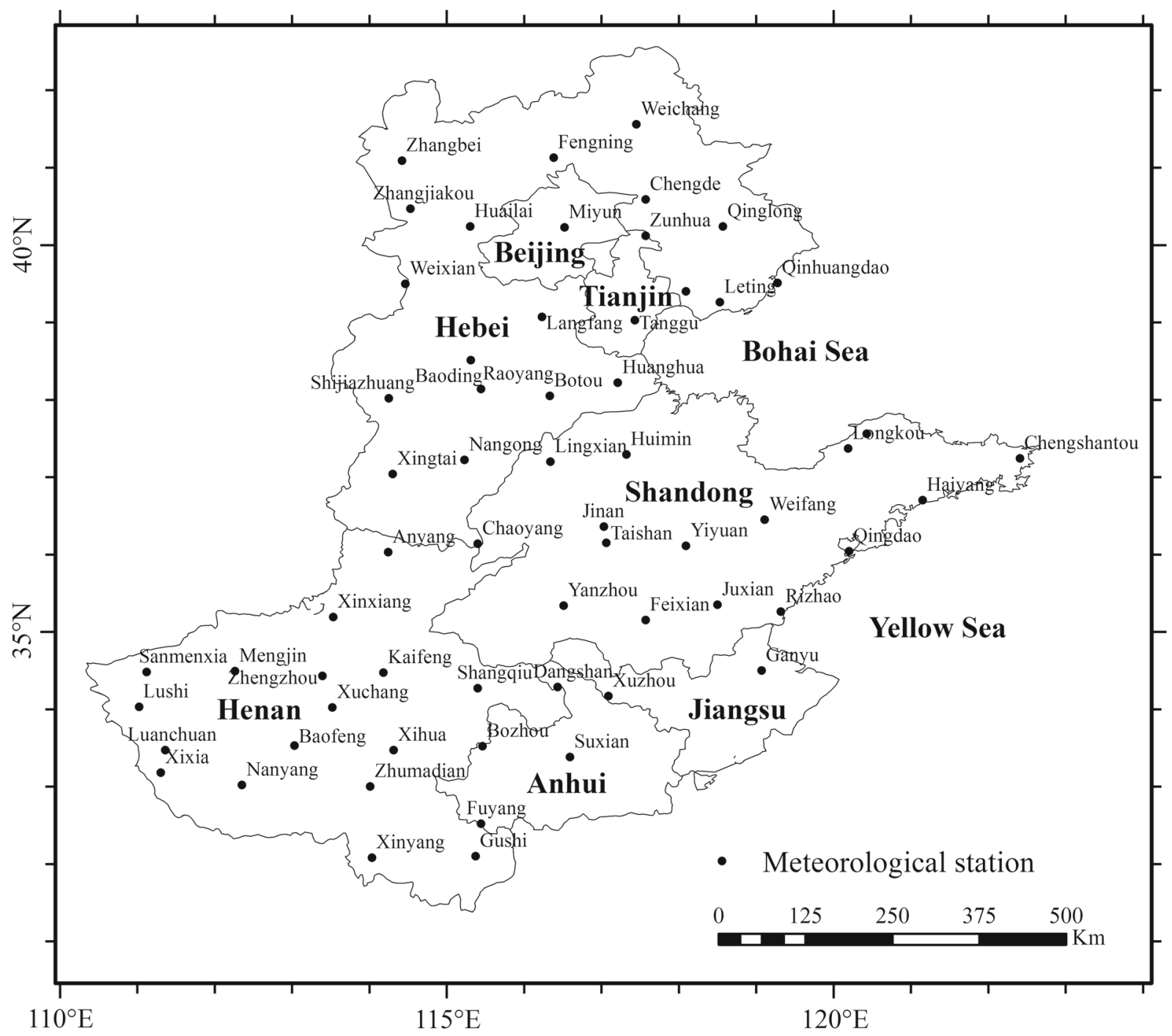

Figure 1. Distribution of meteorological stations on the Huang-Huai-Hai Plain.

\subsection{Methods}

Kriging is a local method of spatial interpolation based on the numerical values of existing regional variables and the structural characteristics of the variation functions. The method includes linear unbiased and optimal estimation of the values of region variables at non-sampled points (Dziubiński and Sitarski 2015; Ning et al. 2015). Ordinary kriging does not consider global trends and uses local factors to estimate the values at non-sampled points to better reflect the spatial variations in precipitation data; therefore, the ordinary kriging method is adopted in this paper. As precipitation is influenced by many factors, such as longitude, latitude and elevation, this paper uses elevation as the covariation term in the ordinary kriging interpolation to spatially determine the precipitation index value at each station based on the precipitation days and precipitation intensity from 1963 to 2012 on the Huang-Huai-Hai Plain.

The linear trend estimation is based on the following univariate linear regression equation:

$$
y=a+b t \quad(t=1,2, \ldots, n),
$$

where $y$ is a certain climatic variable with $n$ samples, $a$ is a regression constant, $b$ is a regression coefficient and $t$ is the corresponding year. The least-squares method is used to estimate $a$ and $b$. The positive and negative values of regression coefficient $a$ represent the increases and decreases in climate variable $y$, while the size of $b$ reflects the degree of probability of a decrease or an increase (Lucie and Mekis 2006; Dan et al. 2015).

The Morlet wavelet analysis method calculates the wavelet transform coefficients and creates a $2 \mathrm{D}$ image through scale expansion and a time 
shift to assess the major cycles of each sequence (Salamalikis et al. 2016). This method can effectively extract information from the time-frequency structure of a climate system through multiscale refinement analysis. Objective separation is performed on structures at different wavelengths, and the amplitude is displayed in the same image for easy analysis. Therefore, in this paper, the Morlet wavelet analysis method is adopted to assess the periodic variations in the number of rainy days and the precipitation intensity.

\section{Results}

\subsection{Spatial variations of precipitation}

\subsubsection{Spatial variation of mean annual precipitation}

Based on the precipitation data, which is observed from 63 meteorological stations on the HuangHuai-Hai Plain, the spatial distributions of the average numbers of annual rainfall days, heavy rain days and rainstorm days and the corresponding precipitation intensities on the Huang-Huai-Hai Plain were determined using the ordinary kriging interpolation (figures 2-4). As shown in figure 2(a), the mean number of annual precipitation days increased progressively from the low-value centre to the outward. The lowest numbers of mean annual precipitation days were concentrated in Baoding, Raoyang, Tangshan, Leting, Xingtai, Nangong, Botou, Huanghua, Langfang in Hebei; and Huimin, Lingxian and Chaoyang in northwest Shandong. These values were $\leq 106.13$ days/annum (d/a). The highest numbers of annual precipitation days were concentrated in Xixia, Xinyang and Gushi in southwest Henan. These values were $\geq 145.09$ d/a. Due to the significant impact of the diverse topography, more precipitation days were observed on the northern Hebei plateau and in the hilly region of Yanshan than in the central plains. Additionally, the number of precipitation days along the Bohai coast is smaller than that along the coast of the Yellow Sea. The precipitation intensity exhibits a zonal distribution and decreases from southeast to northwest. The spatial distribution of the mean precipitation intensity in Shandong Province is not consistent with the overall trend and decreases from the central mountains to the northeast (figure $2 \mathrm{~b}$ ). High-value regions of precipitation intensity are mainly concentrated in Gushi, Xinyang, Zhumadian and Xihua in Henan; Bozhou,
Fuyang, Dangshan and Suxian in Anhui; Yanzhou, Taishan, Ji'nan, Yiyuan, Feixian and Juxian in Shandong; and Xuzhou and Ganyu in Jiangsu. Intensities in these areas exceed $6.37 \mathrm{~mm}$. Lowvalue areas are concentrated in Zhangjiakou and Zhangbei in northwestern Hebei and are characterised with the values below $3.54 \mathrm{~mm}$.

\subsubsection{Spatial variation of extreme precipitation}

The map of heavy rain days exhibits a spatial distribution decreases from the southeast to northwest (figure 3a). Low-value areas of heavy rain days are mainly concentrated in Zhangbei, Zhangjiakou, Huailai, Weixian in northwestern Hebei, and values in these areas are lower than $3.05 \mathrm{~d} / \mathrm{a}$. Highvalue areas are mainly concentrated in Xinyang and Gushi in southern Henan, and values in these areas exceed $6.39 \mathrm{~d} / \mathrm{a}$. The spatial distribution of the heavy rain intensity is relatively uniform, with few differences in different regions. The intensity range is between 32.09 and $34.99 \mathrm{~mm}$, with the largest values exceeding $34.56 \mathrm{~mm}$ in northern coastal areas and most of Shandong Province. Conversely, the heavy rain intensity in Zhangbei, Hebei, is lower than $32.97 \mathrm{~mm}$ (figure 3b).

The spatial distribution of rainstorm days is similar to that of heavy rain and gradually decreases from southeast to northwest (figure 4a). The numerical values of rainstorm days in the highvalue region of southern Henan, northern Anhui, northwestern Jiangsu and the low-value region of northwestern Hebei are considerably different at 3.89 and $0.08 \mathrm{~d} / \mathrm{a}$, respectively. Due to the monsoon climate and topography in the eastern part of the study area, the difference between the number of rainstorm days in the western and eastern areas of Jiangsu and Shandong are relatively large, with the highest value of $2.93 \mathrm{~d} / \mathrm{a}$ in the western areas, while the eastern coastal areas are characterised by values lower than $2.44 \mathrm{~d} / \mathrm{a}$. The spatial distribution of the rainstorm intensity also decreases from southeast to northwest, and the range of highvalue areas is relatively large. Most of these areas are distributed in southeastern Shandong Province and Henan Province, northwestern Anhui Province and northern Jiangsu Province, as well as along the northeastern coast of Hebei. The intensity exceeds $76.49 \mathrm{~mm}$ in the areas. Conversely, lowvalue areas are distributed in Zhangbei, Hebei, and are characterised by values lower than $61.77 \mathrm{~mm}$ (figure 4b). 


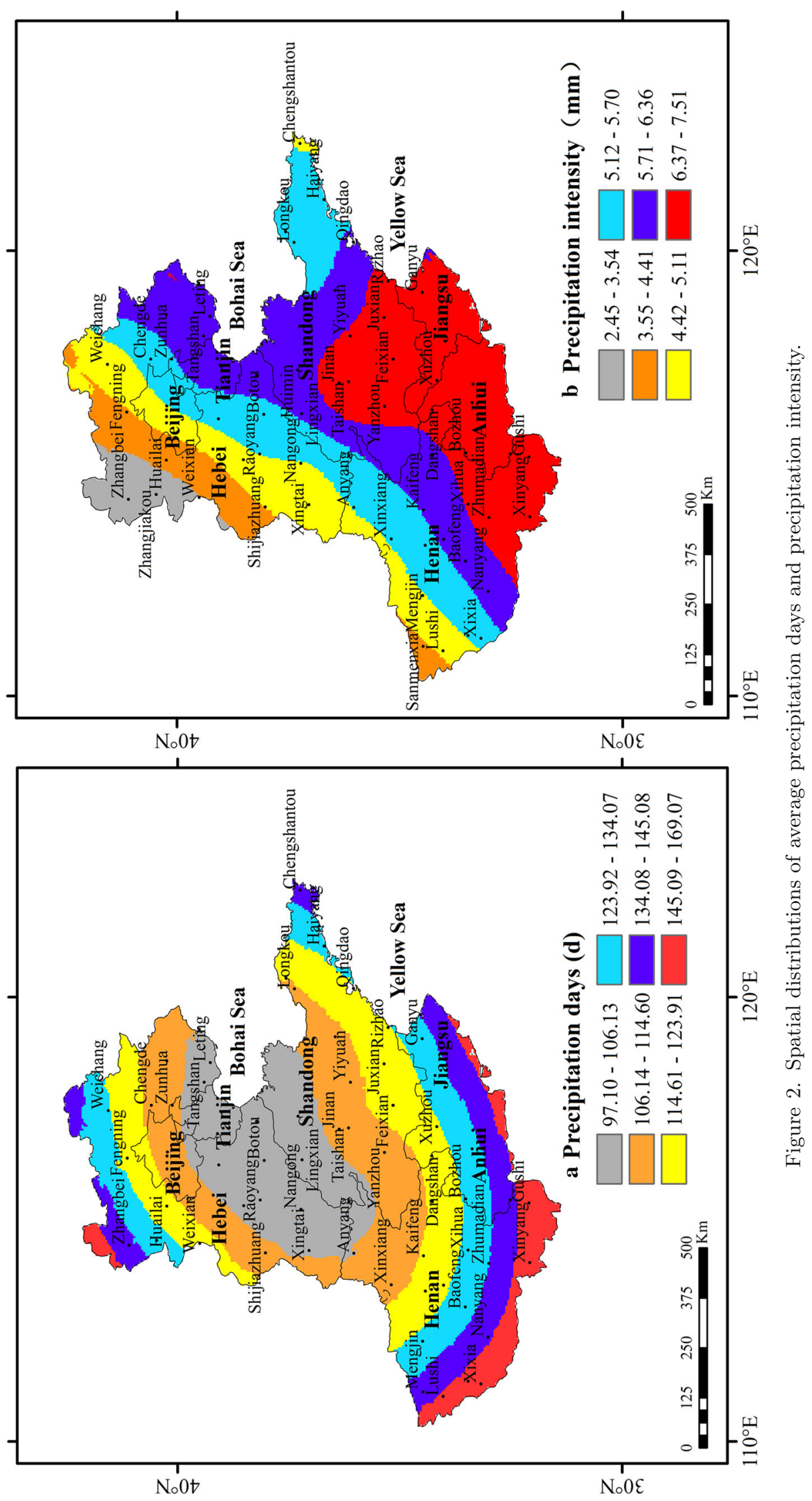




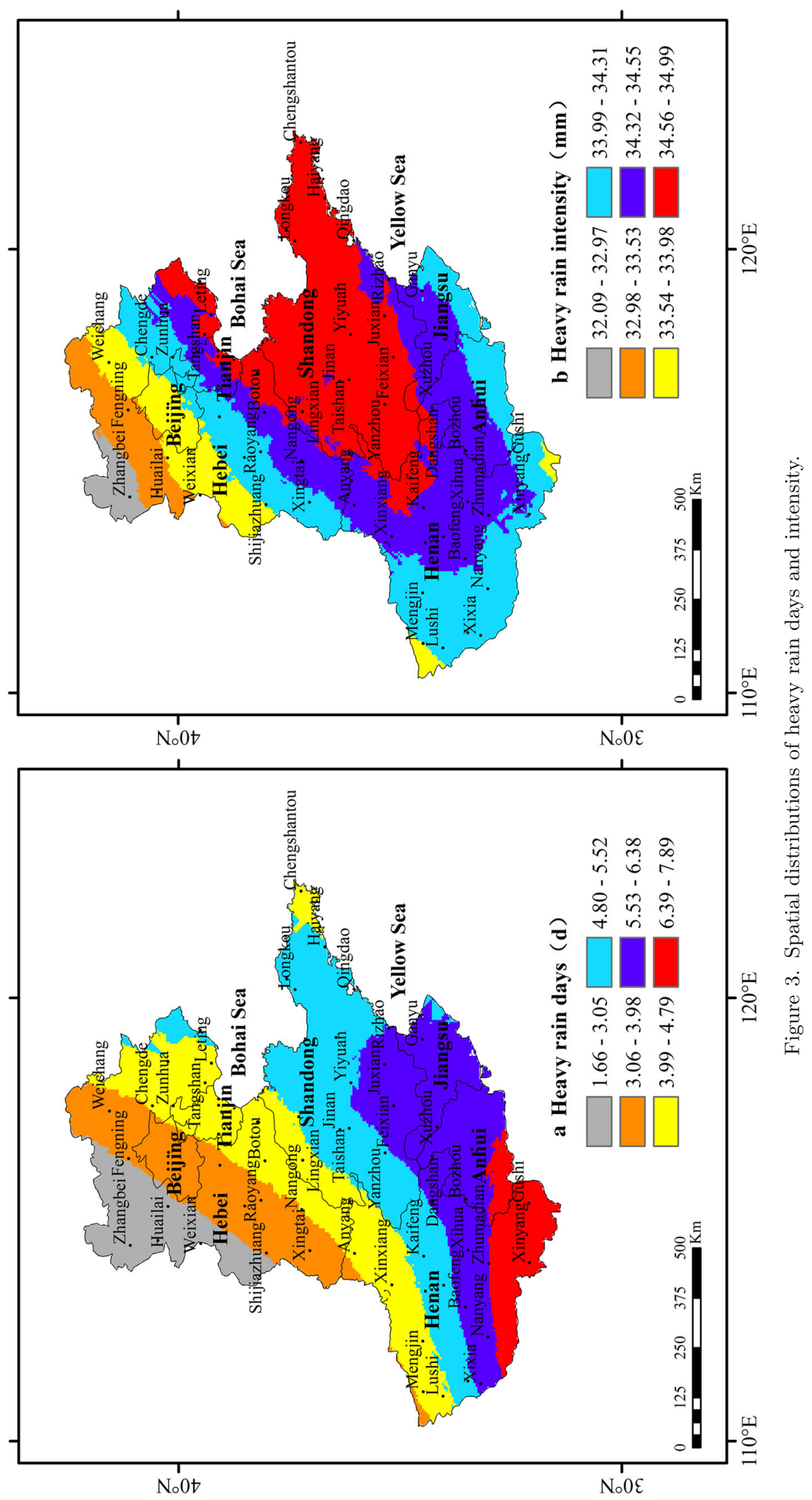




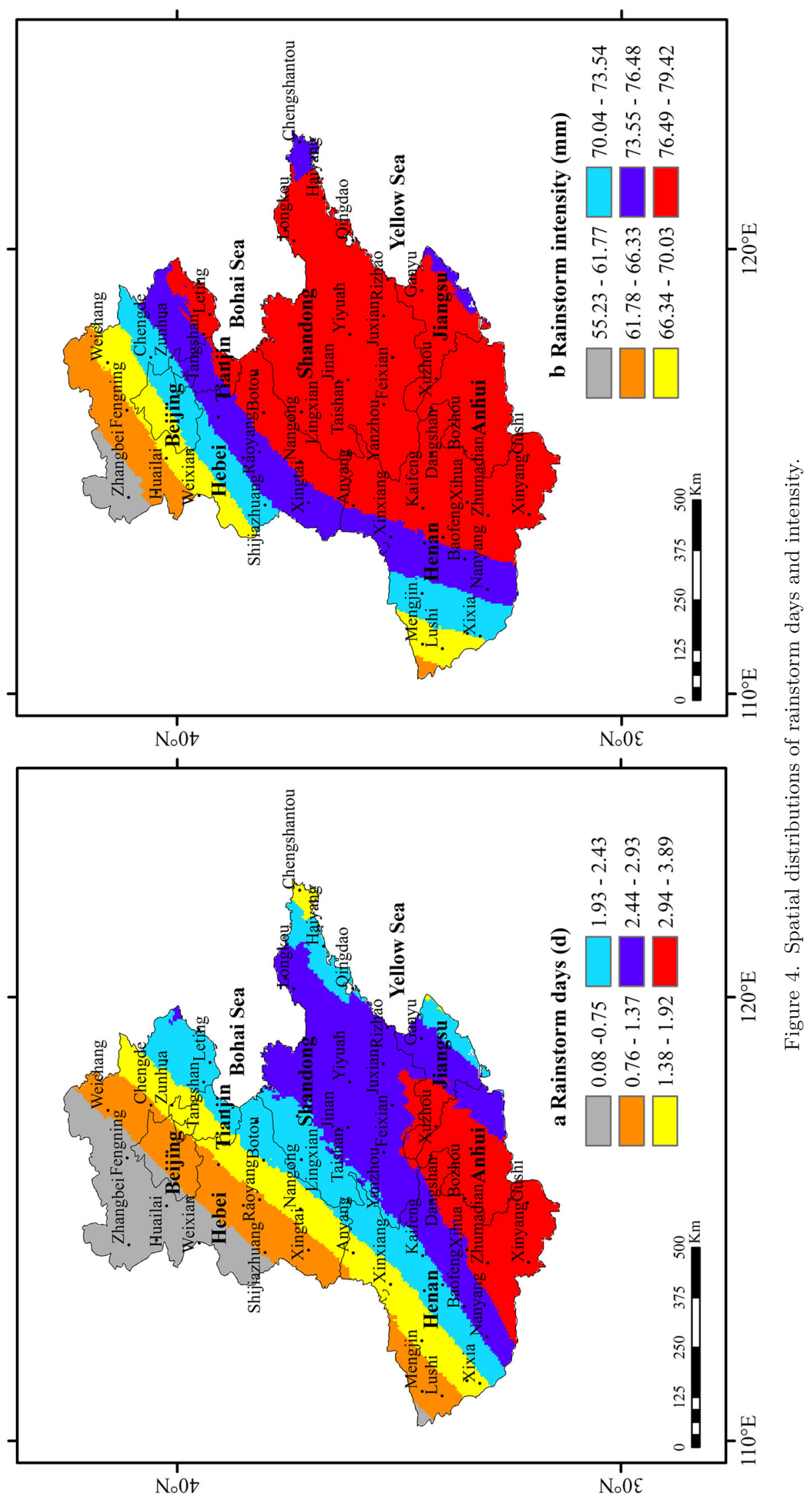




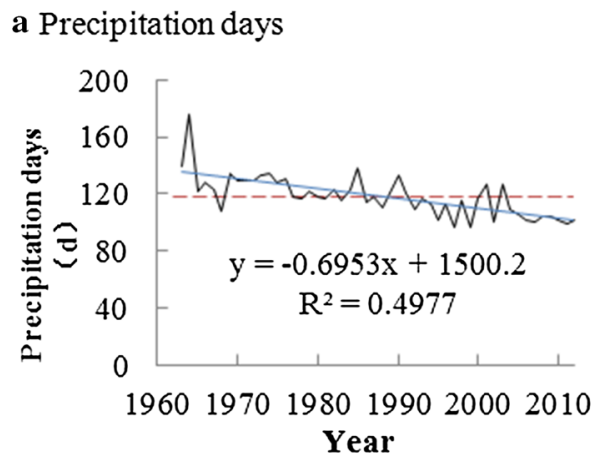

c Heavy rain days

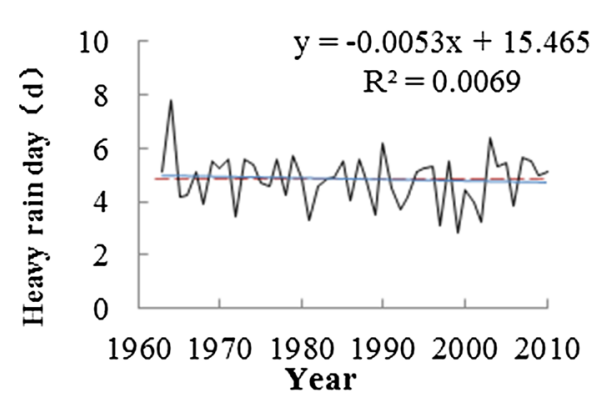

e Rainstorm days

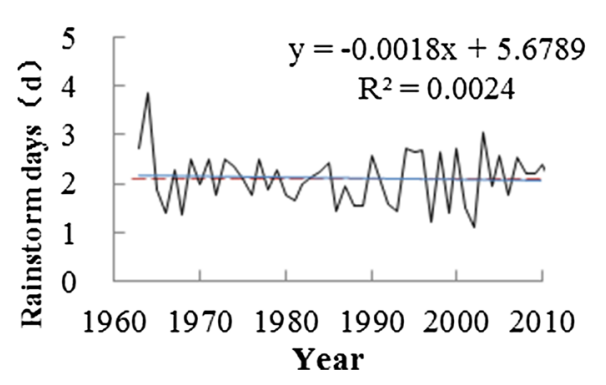

b Precipitation intensity

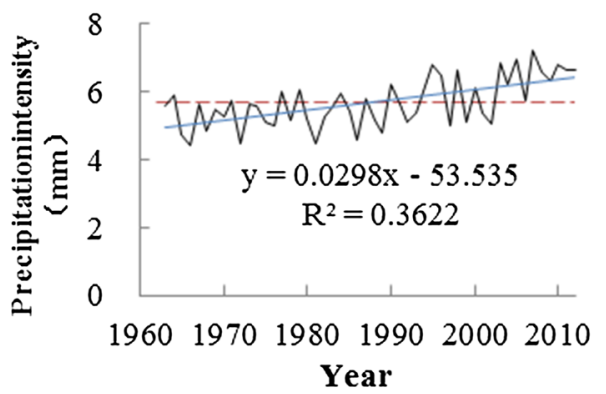

d Heavy rain intensity

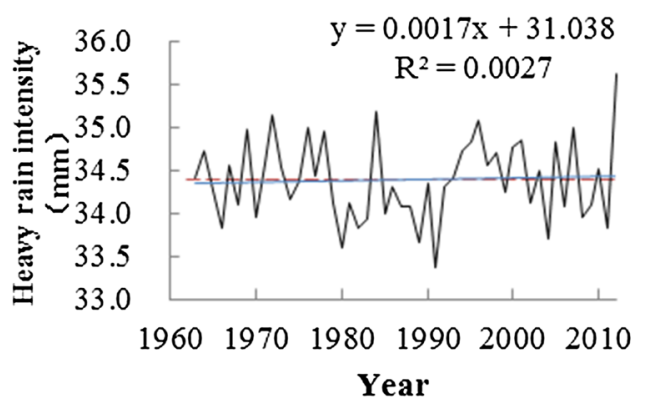

f Rainstorm intensity

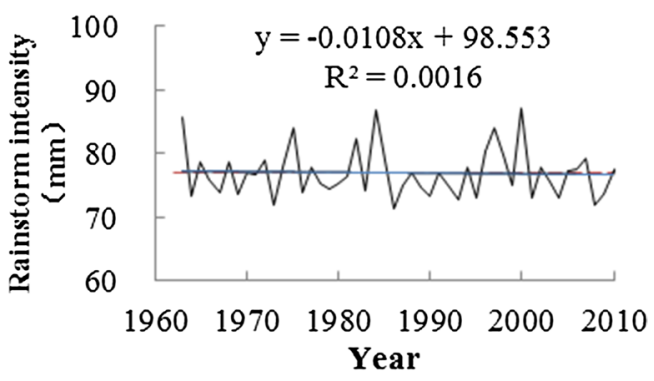

Figure 5. Inter-annual trends in precipitation days and intensity.

\subsection{Temporal variations in precipitation}

\subsubsection{Temporal variations in mean annual precipitation}

The arithmetic mean of each precipitation index was calculated annually at 63 meteorological stations on the Huang-Huai-Hai Plain. Then, as shown in figure $5(\mathrm{a}$ and $\mathrm{b})$, time series of each precipitation index was plotted, and linear trend lines were determined. Temporal variations exist in the number of precipitation days and precipitation intensity, and the total precipitation days display a decreasing trend of $-0.6953 \mathrm{~d} / \mathrm{a}$ with a trend coefficient of 0.4977 . This decreasing trend is extremely significant (correlation coefficient $|r|>r_{0.001}=0.4433$, significant at $P<0.001$ ). The maximum number of precipitation days occurred in 1964 and totalled to $175.59 \mathrm{~d}$, while the minimum value occurred in 1999 and totalled to $96.29 \mathrm{~d}$. In the $1960 \mathrm{~s}$, the precipitation days decreased and varied largely, which decreased from 175.59 to $107.86 \mathrm{~d}$ between 1964 and 1968. The number of precipitation days decreased before 1987, but in most years, it exceeded the average value. After 1987, the number of precipitation days only exceeded the average value in 1990, 2001 and 2003. The precipitation intensity displays an increasing trend of $0.0298 \mathrm{~mm} / \mathrm{a}$ with a trend coefficient of 0.3622 . This increasing trend is extremely significant $(P<0.01)$. The minimum rainfall intensity was observed in 1966, with an average precipitation intensity of $4.40 \mathrm{~mm}$. The precipitation intensity was lower than the average value in most of the years before 1987; however, the precipitation intensity generally exceeded the average value after 1987. 


\subsubsection{Temporal variations in extreme precipitation}

Figure 5(c and d) shows that the overall trend of heavy rain days minimally decreases at -0.0053 $\mathrm{d} / \mathrm{a}$ with a trend coefficient of 0.0069 . However, the trend failed to pass the significant test at $P<0.05$ and is not significant. The largest number of heavy rain days was observed in 1964 (7.79 d), while the smallest was observed in 1999 (2.81 d). The average value of heavy rain days was $4.83 \mathrm{~d}$. Overall, 25 yrs were above and below this value. The intensity of heavy rain increased slightly at $0.0017 \mathrm{~d} / \mathrm{a}$ with a trend coefficient of 0.0027 . However, the trend failed to pass the significance test at $P<0.05$ and is not significant. The mean value of heavy rain intensity was $34.38 \mathrm{~mm}$. Larger than average values were observed in 23 yrs, and smaller than average values were observed in 27 yrs. The maximum value of heavy rain intensity of $35.61 \mathrm{~mm}$ was observed in 2012, and the minimum of 33.38 mm was observed in 1991. This small difference suggests that the variations in heavy rain intensity on the Huang-Huai-Hai Plain over the 50-yr period were relatively stable.

The rainstorm days and intensity trends decreased slowly (figure 5e and f) at -0.0018 and $-0.0108 \mathrm{~d} / \mathrm{a}$, with coefficients of 0.0024 and 0.0016 , respectively. Both trends failed to pass the significant test at $P<0.05$ and are not significant. The maximum number of rainstorm days was observed in 1964 (3.84 d), and the minimum was observed in $2002(1.11 \mathrm{~d})$. The average value of the number of days of heavy rain was $2.11 \mathrm{~d}$. This value was exceeded in 26 yrs and not exceeded in 24 yrs. The maximum value of heavy rainfall intensity of 87.32 $\mathrm{mm}$ was observed in 2000, and the minimum of $71.50 \mathrm{~mm}$ was observed in 1986 . The annual average value was $76.99 \mathrm{~mm}$, which was exceeded in 13 yrs and not exceeded in 37 yrs. (In figure 5, the red dotted line is the mean line and the blue solid line is the trend line.)

\subsubsection{Temporal variations of local regions}

Temporal changes in annual precipitation indices were further quantified in each province on the Huang-Huai-Hai Plain, in order to make a more comprehensive analysis (table 1). Among the six precipitation indices, only the inter-annual variation trend of precipitation days in seven provinces or municipalities was consistent with the overall trend, displaying significant decreasing trends (correlation coefficient $|r|>r_{0.01}=0.3541$, at $P<0.01$ ).
The maximum number of precipitation days occurred in Henan (205.76 d), while the minimum value occurred in Beijing $(78.50 \mathrm{~d})$. The precipitation intensity of Beijing municipality, Hebei province and Tianjin municipality decreased slowly, which were opposite to the overall trend. The largest number of precipitation intensities was in Jiangsu (10.00 d), while the smallest was in Tianjin $(3.18 \mathrm{~d})$. All the trends failed to pass the significant test at $P<0.10$ (correlation coefficient $|r|>r_{0.1}=$ $0.2306)$ and hence are not significant. The heavy rain days of the Henan province increased slightly at $0.0013 \mathrm{~d} / \mathrm{a}$ with a trend coefficient of 0.0200 , while the trends of other provinces or municipalities were consistent with the overall trend. However, the trend failed to pass the significance test at $P<0.1$. The maximum number of heavy rain days was in Anhui $(12.81 \mathrm{~d})$, and the minimum was in Tianjin $(0.50 \mathrm{~d})$. The inter-annual trends of heavy rain intensity in other provinces or municipalities were opposite to the overall trend except in Henan and Tianjin. The maximum value of heavy rain intensity of $44.25 \mathrm{~mm}$ was in Beijing, and the minimum of $16.25 \mathrm{~mm}$ was in Tianjin. Only the variation trend of Anhui province passed the significance test at $P<0.1$. Both the rainstorm days and intensity in Anhui, Henan and Jiangsu province present contrary trends to the general. The maximum number of rainstorm days was in Jiangsu (7.08 d), and the minimum was in Beijing and Tianjin $(0.00 \mathrm{~d})$. The maximum number of rainstorm intensities was in Beijing (105.03 $\mathrm{mm}$ ), and the minimum was in Beijing and Tianjin $(0.00 \mathrm{~mm})$. However, only the variation trend of rainstorm days in Jiangsu province, the variation trend of rainstorm intensity in Jiangsu, Anhui, Hebei province and Beijing municipality passed the significance test at $P<0.1$.

\subsection{Spatial distribution of inter-annual precipitation variations}

\subsubsection{Spatial distribution of annual average precipitation}

Figure 6(a) shows that the trend in the number of precipitation days at each station on the HuangHuai-Hai Plain decreases from northwest to southeast. The daily trend in precipitation days at each station ranged from -0.476 to $-1.025 \mathrm{~d} / \mathrm{a}$, and trends were significant $(P<0.05)$ at 61 stations. The highest decreases in precipitation days were concentrated at the Qingdao, Weifang, Longkou, 
Table 1. Values of minimum, maximum, coefficient of variation (CV) and trends of precipitation indices in each province.

\begin{tabular}{|c|c|c|c|c|c|}
\hline Indices & Province & Min. & Max. & $\mathrm{CV}$ & Trend \\
\hline \multirow[t]{7}{*}{ Precipitation days } & Anhui & 131.56 & 202.00 & 0.5604 & -0.5659 \\
\hline & Beijing & 78.50 & 153.50 & 0.3630 & -0.3219 \\
\hline & Hebei & 85.65 & 154.90 & 0.6716 & -0.6362 \\
\hline & Henan & 107.71 & 205.76 & 0.5862 & -0.6928 \\
\hline & Jiangsu & 123.42 & 200.67 & 0.6572 & -0.7460 \\
\hline & Shandong & 83.31 & 173.50 & 0.7308 & -0.8415 \\
\hline & Tianjin & 79.00 & 149.50 & 0.6176 & -0.6381 \\
\hline \multirow[t]{7}{*}{ Precipitation intensity } & Anhui & 4.92 & 9.87 & 0.0173 & 0.0019 \\
\hline & Beijing & 3.24 & 7.96 & 0.1924 & -0.0195 \\
\hline & Hebei & 3.41 & 7.24 & 0.0045 & -0.0003 \\
\hline & Henan & 3.66 & 7.53 & 0.0300 & 0.0026 \\
\hline & Jiangsu & 4.14 & 10.00 & 0.1034 & 0.0110 \\
\hline & Shandong & 4.23 & 8.24 & 0.1105 & 0.0113 \\
\hline & Tianjin & 3.18 & 9.19 & 0.0200 & -0.0023 \\
\hline \multirow[t]{7}{*}{ Heavy rain days } & Anhui & 4.69 & 12.81 & 0.0906 & -0.0103 \\
\hline & Beijing & 1.00 & 11.50 & 0.0539 & -0.0078 \\
\hline & Hebei & 1.95 & 6.50 & 0.0860 & -0.0060 \\
\hline & Henan & 2.82 & 8.88 & 0.0200 & 0.0013 \\
\hline & Jiangsu & 3.58 & 9.50 & 0.0400 & -0.0017 \\
\hline & Shandong & 2.44 & 9.06 & 0.2243 & -0.0036 \\
\hline & Tianjin & 0.50 & 9.50 & 0.0141 & -0.0320 \\
\hline \multirow[t]{7}{*}{ Heavy rain intensity } & Anhui & 32.82 & 36.09 & 0.2423 & -0.0129 \\
\hline & Beijing & 29.30 & 44.25 & 0.1432 & -0.0306 \\
\hline & Hebei & 25.96 & 35.73 & 0.0970 & -0.0147 \\
\hline & Henan & 30.40 & 37.24 & 0.0032 & 0.0161 \\
\hline & Jiangsu & 32.86 & 36.51 & 0.0141 & -0.0002 \\
\hline & Shandong & 29.87 & 36.17 & 0.1597 & -0.0014 \\
\hline & Tianjin & 16.25 & 42.28 & 0.0283 & 0.0094 \\
\hline \multirow[t]{7}{*}{ Rainstorm days } & Anhui & 1.31 & 7.06 & 0.2102 & 0.0163 \\
\hline & Beijing & 0.00 & 5.00 & 0.2256 & -0.0195 \\
\hline & Hebei & 0.25 & 3.15 & 0.2005 & -0.0080 \\
\hline & Henan & 1.00 & 4.00 & 0.0735 & 0.0036 \\
\hline & Jiangsu & 0.67 & 7.08 & 0.2360 & 0.0160 \\
\hline & Shandong & 0.75 & 5.06 & 0.0265 & -0.0015 \\
\hline & Tianjin & 0.00 & 4.50 & 0.1010 & -0.0075 \\
\hline \multirow[t]{7}{*}{ Rainstorm intensity } & Anhui & 55.17 & 94.39 & 0.3114 & 0.1894 \\
\hline & Beijing & 0.00 & 105.03 & 0.0224 & -0.4294 \\
\hline & Hebei & 13.88 & 71.23 & 0.2364 & -0.2040 \\
\hline & Henan & 37.71 & 84.83 & 0.2404 & 0.0153 \\
\hline & Jiangsu & 28.98 & 89.55 & 0.2518 & 0.1601 \\
\hline & Shandong & 36.28 & 90.72 & 0.0361 & -0.0241 \\
\hline & Tianjin & 0.00 & 104.75 & 0.0831 & -0.1265 \\
\hline
\end{tabular}

Haiyang and Chengshantou stations on the northern coast of Shandong. In these areas, the trend exceeded $-0.842 \mathrm{~d} / \mathrm{a}$, and the maximum was $-1.025 \mathrm{~d} / \mathrm{a}$. The areas with the smallest decreases in the number of precipitation days were concentrated in Zhangjiakou, Huailai, Weixian, Baoding, Shijiazhuang, Langfang, Fengning, Weixian, Xingtai, Nangong, Raoyang in western Hebei; Xinxiang and Zhengzhou in northwest Henan; and Miyun in Beijing. In these areas, the trend was lower than $-0.607 \mathrm{~d} / \mathrm{a}$, with a minimum of $-0.476 \mathrm{~d} / \mathrm{a}$.

The annual average value of the precipitation intensity displayed an increasing trend from northwest to southeast (figure 6b). The precipitation intensity trend at each station varied from 0.007 to $0.048 \mathrm{~mm} / \mathrm{a}$, and trends at 40 stations were 


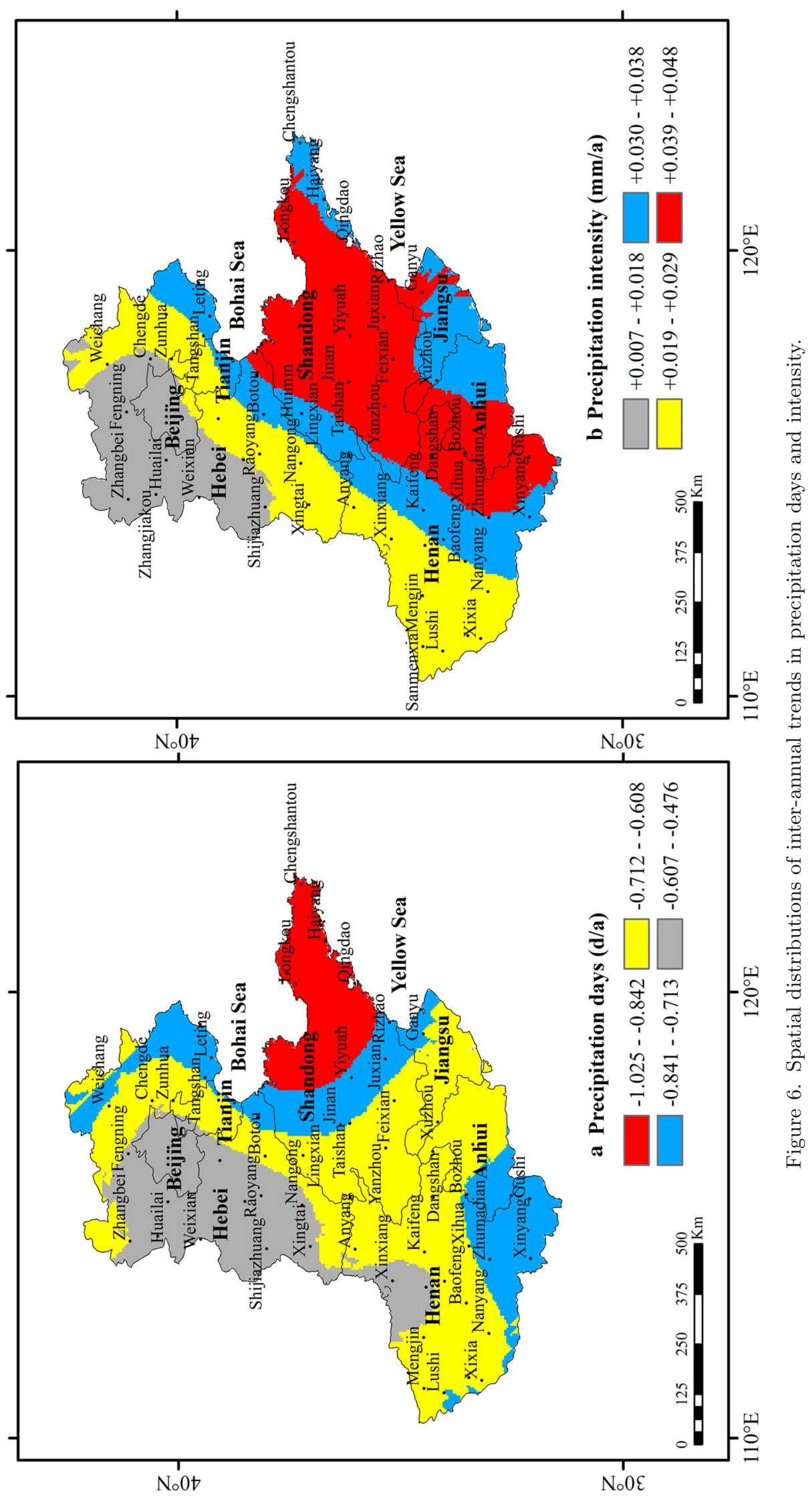


significant $(P<0.05)$. Areas with the highest increasing trends were concentrated in central Shandong, southeast Henan and northwest Anhui. In these areas, the trend exceeded $0.039 \mathrm{~mm} / \mathrm{a}$, and the maximum value was $0.048 \mathrm{~mm} / \mathrm{a}$. Areas with small increasing trends were concentrated in Zhangbei, Zhangjiakou, Weixian, Huailai, Chengde, Fengning, Shijiazhuang, Baoding in northwest Hebei and Miyun in Beijing. In these areas, the trend was lower than $0.018 \mathrm{~mm} / \mathrm{a}$, and the minimum value was $0.007 \mathrm{~mm} / \mathrm{a}$.

\subsubsection{Spatial distribution of inter-annual variations in extreme precipitation}

The inter-annual variation in the number of heavy rain days decreased from southwest to northeast, but the decreasing trend was generally not significant, as only two stations passed the significance test $(P<0.05)$. This trend exhibited high spatial variability, with the highest increasing regions concentrated in mountainous areas and the highest decreasing regions concentrated along the coast. The trends in heavy rain days in Sanmenxia, Luanchuan, Xixia, Lushi, Mengjin, Nanyang, Xuchang, Baofeng in western Henan; Shijiazhuang, Weixian, Xingtai, Zhangjiakou, Baoding, Raoyang in western Hebei; Ji'nan, Taishan, Yiyuan, Yanzhou and Feixian in central Shandong showed weak increasing trends, with a maximum increase of $0.015 \mathrm{~d} / \mathrm{a}$. Other stations showed slight decreasing trends, with a maximum decrease of -0.024 $\mathrm{d} / \mathrm{a}$ (figure $7 \mathrm{a}$ ). The inter-annual variation in heavy rain intensity increased progressively from northeast to southwest, but the increasing trend was generally not significant, as only two stations passed the significance test $(P<0.05)$. The highest increasing regions were concentrated in western Henan, with a maximum increase of $0.036 \mathrm{~mm} / \mathrm{a}$, and the highest decreasing regions were concentrated in central Hebei, and the maximum decrease was $-0.034 \mathrm{~mm} / \mathrm{a}$ (figure $7 \mathrm{~b}$ ).

The inter-annual variations in rainstorm days and rainstorm intensity displayed decreasing trends from southeast to northwest; however, the decreasing trends were generally not significant, as four and five stations, respectively, passed the significance test $(P<0.05)$. The highest decreasing regions were concentrated in most parts of Beijing, Tianjin and Hebei. Values in these areas ranged from -0.013 to $-0.007 \mathrm{~d} / \mathrm{a}$, and the highest increasing regions were concentrated in southern Shandong, northern Jiangsu, northern Anhui, central and southern Henan. Values in these regions ranged from 0.003 to $0.008 \mathrm{~d} / \mathrm{a}$ (figure 8a). The highest decreasing areas of rainstorm intensity were concentrated in southwestern Beijing and central Hebei. Values in these areas ranged between -0.375 and $-0.225 \mathrm{~mm} / \mathrm{a}$, and the highest increasing areas of rainstorm intensity were concentrated in northern Jiangsu, northern Anhui, central Shandong and southeastern Henan. Values in these areas ranged from 0.056 to $0.215 \mathrm{~mm} / \mathrm{a}$. The spatial distributions of rainstorm days and intensity in northern Hebei and the rainstorm intensity along the northeastern coast of Shandong were affected by terrain variations and their locations near the sea or inland (figure $8 \mathrm{~b}$ ).

\subsection{Precipitation - periodic analysis}

Morlet wavelet analysis was performed on the time series of mean annual and extreme precipitation on the Huang-Huai-Hai Plain over the study period, and the real part of the wavelet coefficient contour chart is shown in figure 9. The solid and dashed contour lines represent the precipitation index values. Figure 9(a) shows that the change in the mean number of annual precipitation days oscillated over 4a, 7a, 10a, 13a, 22a and 28a, and the periodic oscillation of $28 \mathrm{a}$ was the strongest in the first portion of the study period. The $22 \mathrm{a}$ and 28a oscillations were observed throughout the entire study period, and the oscillation period of $13 \mathrm{a}$ became obvious after 1985. Additionally, the oscillation periods of $10 \mathrm{a}$ and $4 \mathrm{a}$ were observed before 1970, while the oscillation period of $7 \mathrm{a}$ was observed from approximately 1985 to 1990.

The precipitation intensity's oscillation periods are $5 \mathrm{a}, 7 \mathrm{a}, 10 \mathrm{a}, 17 \mathrm{a}$ and $28 \mathrm{a}$. The periodic oscillation of $28 \mathrm{a}$ was the strongest, and the $28 \mathrm{a}$ and 5 a oscillations were observed throughout the entire study period. The oscillation period of 17a was observed after 1980, and the oscillation period of 10a was observed before 1970. Additionally, the oscillation period of 7 a was observed from approximately 1985 to 1990 (figure 9b).

Heavy rain days' oscillation periods are $5 \mathrm{a}, 7 \mathrm{a}$, 10a, 15a, 22a and 28a. The periodic oscillation of $28 \mathrm{a}$ was the main variation and was the most observed throughout the 50-yr period. The oscillation period of 7 a was observed after 1975, and the oscillation period of 10a was observed before 1980 and became more obvious after 2000. Additionally, the oscillation period of $15 \mathrm{a}$ became obvious after 


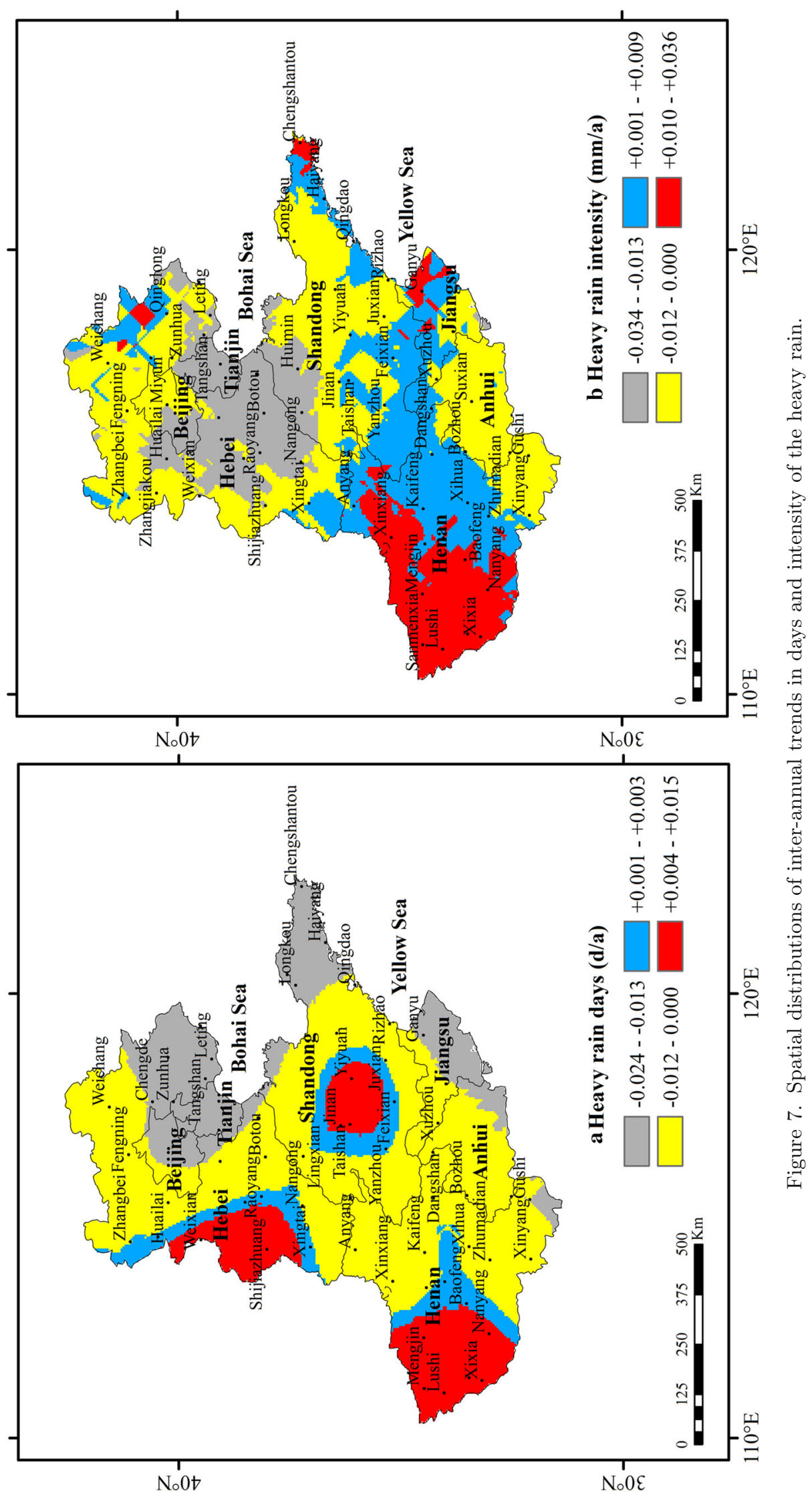




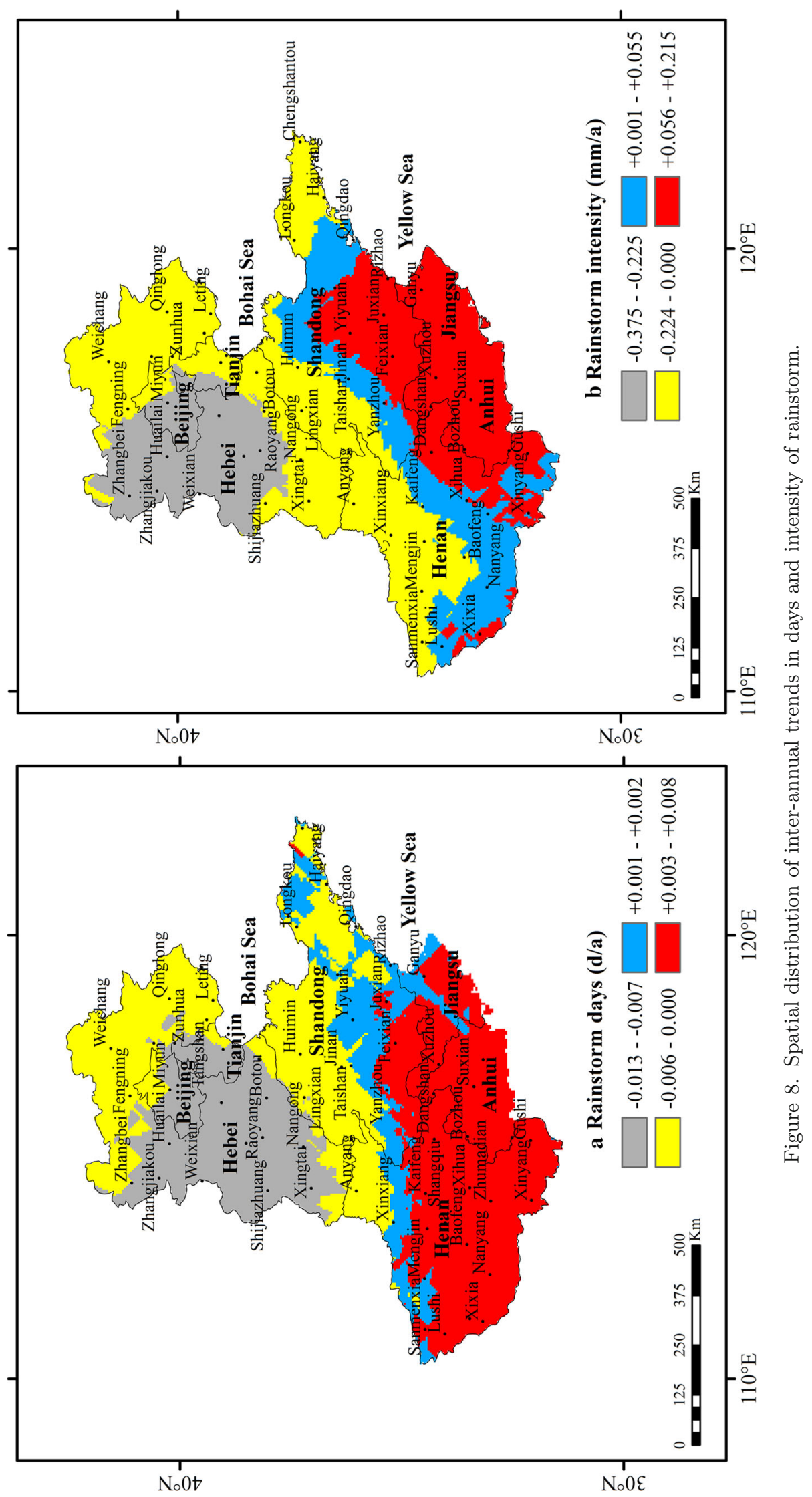


a Precipitation days

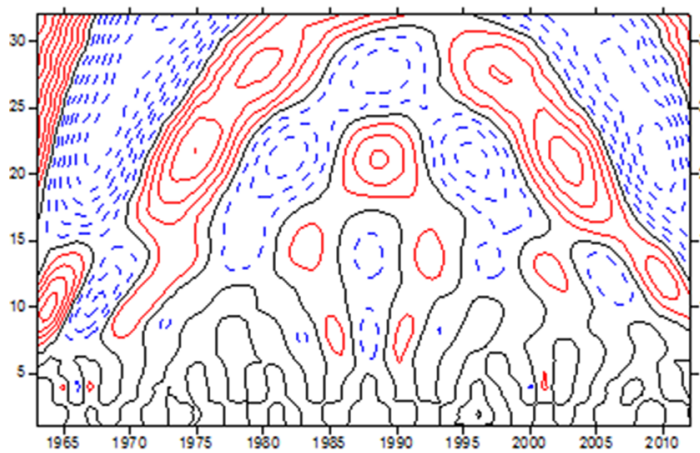

c Heavy rain days

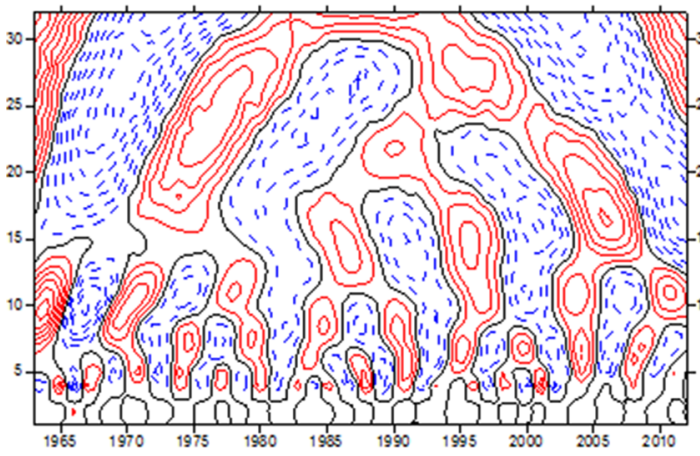

e Rainstorm days

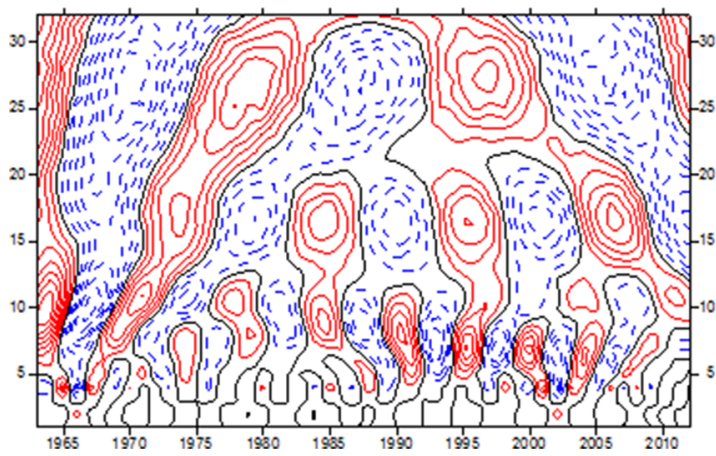

b Precipitation intensity

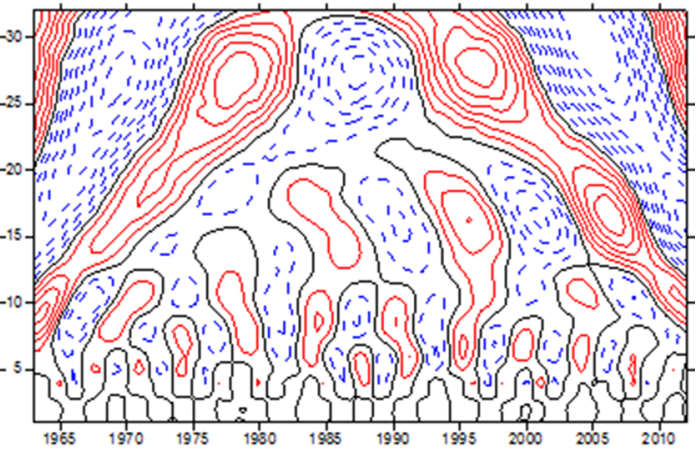

d Heavy rain intensity

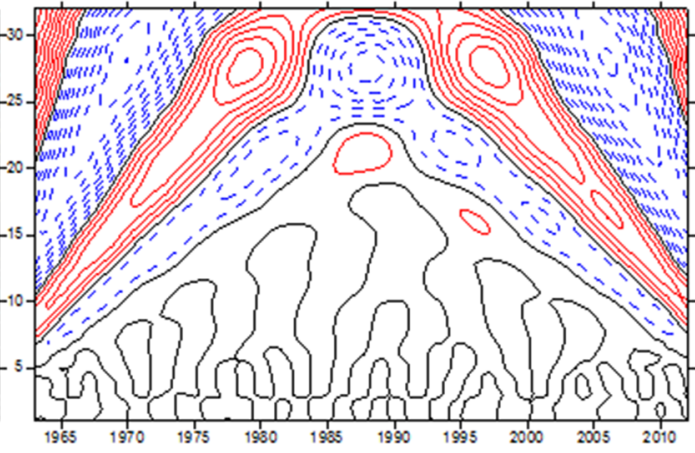

f Rainstormintensity

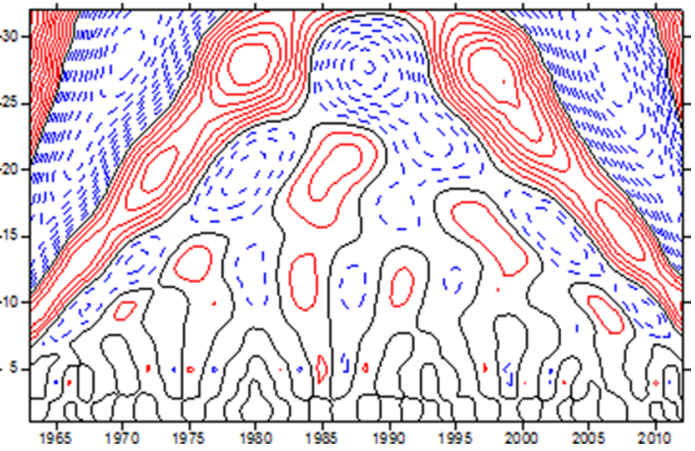

Figure 9. Periodic cycles in precipitation days and intensity from 1963 to 2012.

1985, when the 5a period was not obvious. The period of 22a only appeared between 1990 and 1995 (figure 9c). There were three different periods of heavy rain intensity: $15 \mathrm{a}, 22 \mathrm{a}$ and $28 \mathrm{a}$. The $28 \mathrm{a}$ oscillation was strongest in the first portion of the period but occurred throughout the entire period. Additionally, the 15a oscillation was only observed after 1998, and the period of 22 a was most obvious from approximately 1980 to 2000 (figure 9d).

Rainstorm days exhibited oscillation periods of 4a, 7a, 10a, 16a and 28a, and the oscillation period of $28 \mathrm{a}$ was the strongest and observed throughout the entire study period. The $4 \mathrm{a}$ variation was not obvious, and the 7 a period was observed between 1980 and 1990. Additionally, the 10a period appeared before 1995 and after 2005, and 16a was observed throughout the entire study period (figure 9e). Rainstorm intensity displayed oscillation periods of 5a, 10a, 13a, 15a, 20a and 28a, and the oscillation period of 28a was most obvious in the first portion of the period. The time scale of $5 \mathrm{a}$ was not obvious, and the period of 10a was most obvious from approximately 1985 to 2000 . Additionally, the periods of $13 \mathrm{a}$ and $15 \mathrm{a}$ were relatively obvious before 1985 and after 2000, and the oscillation periods of $20 \mathrm{a}$ and $28 \mathrm{a}$ were observed throughout the entire time series (figure 9f).

The wavelet analysis of precipitation can be divided into two more than normal precipitation periods and three less than normal precipitation 
periods on the 28a scale (figure 9). Among them, significant interdecadal climate shift around the late 1970s exists, with more severe drought on Huang-Huai-Hai Plain since then. This conclusion is consistent with the conclusions of other researchers (Huang et al. 2006; Gu et al. 2007; Fu et al. 2009). The difference of meridional position of the summer East Asian upper-tropospheric Jet Stream (EAJS) and West Pacific Subtropical High (WPSH) before and after 1970s was one of the most important reasons for the transition of rainfall pattern. Besides, decadal global SST variations in both the extratropical northern Pacific and the tropical Pacific may have played a substantial role in this climate shift (Mantua et al. 1997; Gu et al. 2007).

\section{Conclusion}

Based on daily precipitation data observed from 1963 to 2012 on the Huang-Huai-Hai Plain, the kriging, trend analysis and Morlet wavelet analysis methods were used to analyse the number of precipitation days and precipitation intensity as research indices. The study of the spatio-temporal characteristics of the spatial distributions, interannual variations and precipitation periodicity of precipitation events on the Huang-Huai-Hai Plain led to the following conclusions.

Overall, the highest numbers of mean annual precipitation days on the Huang-Huai-Hai Plain from 1963 to 2012 are centred in southwestern Shandong, southeastern Hebei, southern Beijing and southcentral Tianjin. These values increase outward progressively, and the annual average precipitation intensity exhibits an obvious zonal distribution that decreases from southeast to northwest. The distribution characteristics of the extreme precipitation index are similar to those of the average precipitation intensity over the study period. Annual average values of precipitation days and heavy rain days exhibited decreasing trends, while precipitation intensity and heavy rain intensity exhibited gradual increasing trends. Additionally, the inter-annual variations of rainstorm days and intensity displayed slight decreasing trends. Among the six precipitation indices, only the inter-annual variation trend of precipitation days in seven provinces or municipalities was consistent with the overall trend. The variations of other five precipitation indices in different provinces or municipalities present contrary tendency to the overall trends.
The annual number of precipitation days at each station on the Huang-Huai-Hai Plain exhibits descending trends and decreases from northwest to southeast. The largest reductions were observed along the northern coast of Shandong Peninsula, and the smallest reductions were observed in western Hebei and northwestern Henan. The average precipitation intensity increased from northwest to southeast. The largest increase was observed in central Shandong, while the smallest increase was observed in northwestern Hebei. The inter-annual variation in days of heavy rain decreased progressively from southwest to northeast and was not significant. Conversely, the inter-annual variation in heavy rain intensity increased progressively from northeast to southwest, but this trend was also not significant. In contrast, the inter-annual variations in rainstorm days and heavy rain intensity both exhibited decreasing trends from southeast to northwest, but these trends were also not significant.

The Morlet wavelet analysis showed that the precipitation index had different periodic oscillations during the study period, and differences were observed in precipitation index values at different time scales. Moreover, the mean annual values of precipitation days, rainfall intensity, days of heavy rain, heavy rain intensity, the number of rainstorm days and rainstorm intensity all exhibited a periodic oscillation of 28a. Additionally, the mean annual values of precipitation days, rainfall intensity, days of heavy rain, heavy rain intensity, the number of rainstorm days and rainstorm intensity, all had a periodic oscillation of 10a. We believe that each station in the region has its unique precipitation cycles, and in further studies we plan to focus on the unique variation patterns of each station.

Influenced by the factors of climate background and the underlying surface, regional differences of the spatial and temporal characteristics were obvious. At the regional level, all grades of rainfall days decreased, and the rainfall intensity increased except the rainstorm intensity. The continuous decrease in precipitation days has resulted in the serious drought on the Huang-Huai-Hai Plain, and the intensification of precipitation intensity also caused the frequent occurrence of extreme precipitation events in the region, which resulted in severe flooding. At the station level, the spatial distribution of precipitation indices decreased with the increase of latitude from southeast to northwest, and increased from west to east in equal latitudes. For annual average precipitation, the variation 
trends of each station were consistent with the overall trends. Although for extreme precipitation the variation trends of several stations were opposite to the overall trends, these stations were mainly in mountainous areas of heavy rain days and intensity and in the Huai River Basin of rainstorm days and intensity.

Climate change includes variations in precipitation, temperature and other meteorological factors, and the associated spatial and temporal distributions are important. Notably, precipitation variations might affect the agricultural production in China. The impacts of variations in the temporal and spatial distributions and frequencies of different threshold precipitation values on agricultural production should be considered. The effects of precipitation conditions on the development, yield and quality of crop production in key growth stages of different crops should be analysed. For instance, continuous wet weather in the summer maize flowering period could decrease the grain number and yield of maize on the Huang-Huai-Hai Plain, and field crop grain mildew affected the grain quality due to continuous wet weather during the harvest period. In future research, it is necessary to combine the suitable meteorological indices with actual precipitation observations and obtain the data in different stages of crop growth to more accurately assess the food production variations and other socio-economic issues caused by precipitation extremes.

\section{Acknowledgements}

This research was supported by the National Basic Program of China (973 Program) No. 2012CB955800, the National Natural Science Foundation of China (Nos. 41671536 and 41501588), the Postdoctoral fund (2016M602232) and the Key Scientific Research Projects in Colleges and Universities (Nos. 17A170005 and 18A170002).

\section{References}

Beguería S, Angulo-Martínez M, Vicente-Serrano S M, López-Moreno J I and El-Kenawy A 2011 Assessing trends in extreme precipitation events intensity and magnitude using non-stationary peaks-over-threshold analysis: A case study in northeast Spain from 1930 to 2006; Int. J. Climatol. 31(14) 2102-2114.

Ci H, Zhang Q, Zhang J, Bai Y and Liu J 2014 Spatiotemporal variations of extreme precipitation events within
Xinjiang during 1961-2010; Geogr. Res. 33(10) 18811891, https://doi.org/10.11821/dlyj201410009 (in Chinese).

Dan S, Sharma V and Juyal V 2015 Observed linear trend in few surface weather elements over the northwest Himalayas (NWH) during winter season; $J$. Earth Syst. Sci. 124(3) 553-565, https://doi.org/10. 1007/s12040-015-0560-2.

Dong X, Gu W, Meng X and Liu H 2014 Change features of precipitation events in Shandong Province from 1961 to 2010; Acta Geogr. Sin. 69(5) 661-671, https://doi.org/10. 11821/dlxb201405009 (in Chinese).

Dziubiński I and Sitarski R 2015 A multivariate regression model for predicting precipitation in the Daqing mountains; Mt. Res. Dev. 28(28) 318-325.

Fan L, Lu C H, Yang B and Chen Z 2012 Long-term trends of precipitation in the north China plain; $J$. Geogr. Sci. 22(6) 989-1001, https://doi.org/10.1007/ s11442-012-0978-2.

Frich P, Alexander L V, Della-Marta P, Gleason B, Haylock M, Klein Tank A M G and Peterson T 2002 Observed coherent changes in climatic extremes during the second half of the twentieth century; Climatol. Res. 19 193-212, https://doi.org/10.3354/cr019193.

$\mathrm{Fu}$ J, Li S and Luo D 2009 Impact of global SST on decadal shift of East Asian summer climate; Adv. Atmos. Sci. 26(2) 192-201, https://doi.org/10.1007/ s00376-009-0192-z.

Gu W, Li C and Pan J 2007 Relationship between interdecadal variation of North Pacific-Equatorial Indian Ocean SST and transition of rainfall pattern in East China around the 1970s; Climatol. Environ. Res. 12(2) 113123, https://doi.org/10.3878/j.issn.1006-9585.2007.02.01 (in Chinese).

Gu X, Zhang Q and Zhang S 2016 Spatio-temporal properties of flood/drought hazards and possible causes and impacts in 1961-2010; Sci. Geogr. Sin. 36(3) 439-447, https://doi.org/10.13249/j.cnki.sgs.2016.03.016 (in Chinese).

Guo E, Zhang J, Si H, Dong Z, Cao T and Lan W 2016 Temporal and spatial characteristics of extreme precipitation events in the midwest of Jilin province based on multifractal detrended fluctuation analysis method and copula functions; Theor. Appl. Climatol. 1-11, https://doi.org/ 10.1007/s00704-016-1909-4.

He Z and He J 2014 Temporal and spatial variation of extreme precipitation in the Yellow River basin from 1960 to 2012; Res. Sci. 36(3) 490-501 (in Chinese).

Huang R, Cai R, Chen J and Zhou L 2006 Interdecadal variations of drought and flooding disasters in China and their association with the East Asian Climate System; Chin. J. Atmos. Sci. 30(5) 730-743, https://doi.org/10.3878/j. issn.1006-9895.2006.05.02 (in Chinese).

IPCC 2012 Managing the risks of extreme events and disasters to advance climate change adaptation. A special report of working groups I and II of the Intergovernmental Panel on Climate Change; Cambridge University Press, Cambridge and New York, 582p.

Li Y, Hu J, He D and Liu J 2013 Variability of frequency and intensity of heavy rainfall events and its impacts in the Red River Basin during 1960-2007; Geogr. Res. 32(1) 6472, https://doi.org/10.11821/yj2013010007 (in Chinese). 
Liao Y, Chen D and Xie Y 2011 Spatial and temporal distribution of dry spells in China; Acta Geogr. Sin. 67(3) 321-336, https://doi.org/10.11821/xb201203004 (in Chinese).

Liu X, Zhang Z, Shuai J, Wang P, Shi W J, Chen Y and Tao F 2012 Effect of chilling injury on rice yield in Heilongjiang Province; Acta Geogr. Sin. 67(9) 1223-1232, https://doi.org/10.11821/xb201209007 (in Chinese).

Lucie A and Mekis E 2006 Changes in daily and extreme temperature and precipitation indices for Canada over the twentieth century; Atmos.-Ocean. 44(2) 177-193, https:// doi.org/10.3137/ao.440205.

Mantua N, Hare S, Zhang Y, Wallace J and Francis R 1997 A Pacific interdecadal climate oscillation with impacts on salmon production; Bull. Am. Meteorol. Soc. 78 10691079.

Moberg A and Jones P D 2005 Trends in indices for extremes in daily temperature and precipitation in central and western Europe, 1901-99; Int. J. Climatol. 25(9) 1149-1171, https://doi.org/10.1002/joc.1163.

Najafi and Moazami 2016 Trends in total precipitation and magnitude-frequency of extreme precipitation in Iran, 1969-2009; Int. J. Climatol. 36(4) 1863-1872, https:// doi.org/10.1002/joc.4465.

Ning X, Qin Y, Cui Y, Li X and Chen Y 2015 The spatio-temporal change of agricultural hydrothermal conditions in China from 1951 to 2010; Acta Geogr. Sin. 70(3) 392-406, https://doi.org/10.11821/dlxb201503002 (in Chinese).

Parker L E and Abatzoglou J T 2016 Spatial coherence of extreme precipitation events in the Northwestern United States; Int. J. Climatol. 36(6) 2451-2460, https://doi. org/10.1002/joc. 4504 .

Ragab R and Prudhomme C 2002 Climate change and water resources management in arid and semi-arid regions: Prospective and challenges for the 21st century. Biosyst. Eng. 81(1) 3-34.

Rashid M M, Beecham S and Chowdhury R K 2015 Assessment of trends in point rainfall using continuous wavelet transforms; Adv. Water Resour. 82 1-15, https://doi.org/ 10.1016/j.advwatres.2015.04.006.

Ren Z, Zhang M, Wang S, Qiang F, Zhu X and Dong L 2014 Changes in precipitation extremes in South China during 1961-2011; Acta Geogr. Sin. 69(5) 640-649 (in Chinese).

Salamalikis V, Argiriou A and Dotsika E 2016 Periodicity analysis of $\delta^{18} \mathrm{O}$ in precipitation over central Europe: Time-frequency considerations of the isotopic 'temperature' effect; J. Hydrol. 534 150-163.

Trenberth K E 1998 Atmospheric moisture residence times and cycling: Implications for rainfall rates and climate change; Climatol. Change 39(4) 667-694.

Xu X, Zhang X, Dai E and Wei S 2014 Research of trend variability of precipitation intensity and their contribution to precipitation in China from 1961 to 2010; Geogr. Res. 33(7) 1335-1347, https://doi.org/10.11821/ dlyj201407013 (in Chinese).

Yang B, Qing J, Zhang T, Xie S and Ma W 2014 Characteristics of precipitation change from 1961 to 2011 in southeast Chongqing; J. Meteorol. Environ. 30(3) 46-51 (in Chinese).

Yin J, Yan D, Yang Z, Yuan Z, Yuan Y and Zhang C 2016 Projection of extreme precipitation in the context of climate change in Huang-Huai-Hai region, China; $J$. Earth Syst. Sci. 125(2) 1-13, https://doi.org/10.1007/ s12040-016-0664-3.

Zeng Y and Lu E 2015 Changes of summer rainfall and extreme precipitation during 1961-2010 in China; Adv. Climatol. Change Res. 11(2) 79-85, https://doi.org/10. 3969/j.issn.1673-1719.2015.02.001 (in Chinese).

Corresponding editor: K RAJENDRAN 